\title{
Ectopic Expression of Col2.3 and Col3.6 Promoters in the Brain and Association with Leptin Signaling
}

\author{
Erica L. Scheller ${ }^{a}$ Gina M. Leinninger ${ }^{b}$ Kurt D. Hankenson ${ }^{c} \quad$ Martin G. Myers, Jr. ${ }^{b}$ \\ Paul H. Krebsbach ${ }^{a}$

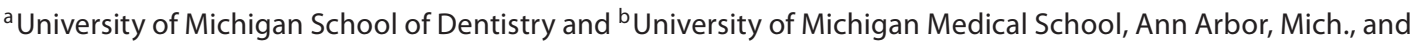 \\ 'University of Pennsylvania, Philadelphia, Pa., USA
}

\section{Key Words}

Leptin · Bone $\cdot$ Collagen promoter $\cdot$ Brain $\cdot$ Leptin receptor

\begin{abstract}
The collagen 2.3 and 3.6 promoters have been used to drive Cre expression for generation of conditional transgenic mutant mice. Within the bone, Col3.6 is expressed by mesenchymal precursor cells and their downstream progeny, while Col2.3 is more osteoblast specific. Our generation of transgenic mice with Col2.3-Cre- and Col3.6-Cre-driven deletion of the long-form leptin receptor (ObRb) necessitated a thorough analysis of the nonspecific expression of these promoters in the central nervous system. Both Col2.3 and Col3.6 were capable of forcing loxP recombination in the brain as demonstrated by EGFP expression in ROSA reporter mice. Expression of Col2.3 was limited to the central base of the brain near the third ventricle. In contrast, robust expression of Col3.6 was noted throughout the brain, centering near the distal third ventricle, third ventricle, and aqueduct. We subsequently analyzed the colocalization of leptin-responsive P-Stat3 neurons with Col3.6-expressing neurons. Approximately $5-10 \%$ colocalization was noted in leptin-responsive brain areas such as the arcuate nucleus, dorsal medial hypothalamus, ventral premammillary nucleus, and lateral hypothalamus. Injection of 3.6 $\mathrm{Cre+F/F}$ ObRb knockout mice with
\end{abstract}

leptin confirmed the presence of an intact P-Stat3 response that was dampened in the lateral hypothalamus $(p<0.050)$. This test was done to explore the contribution of neural leptin signaling to the bone phenotype of the $3.6^{\mathrm{Cre}+\mathrm{F} / \mathrm{F}}$ mice. Our analysis indicates that neural ObRb deletion, while present, is likely not the sole driver of femoral changes through traditional sympathetic circuits.

Copyright $\odot 2011$ S. Karger AG, Base

\section{KARGER}

() 2011 S. Karger AG, Basel

Fax +4161306 1234

E-Mail karger@karger.ch

www.karger.com
Accessible online at: www.karger.com/cto

\section{Abbreviations used in this paper}

3V third ventricle

Arc arcuate nucleus

$\mathrm{Aq}$ aqueduct

Col1A1 collagen $1 \mathrm{~A} 1$

D3V dorsal third ventricle

DMH dorsal medial hypothalamus

EGFP enhanced green fluorescent protein

IP intraperitoneal

KO knockout

LHA lateral hypothalamic area

MPC mesenchymal precursor cell

$\mathrm{ObRb} \quad$ long-form leptin receptor

PMv ventral premamillary nucleus

VMH ventral medial hypothalamus 


\section{Introduction}

We previously reported a significant increase in both femur length and trabecular density in mice with conditional deletion of the long-form leptin receptor $(\mathrm{ObRb})$ driven by Col3.6-Cre (3.6 $\left.{ }^{\mathrm{Cre}+\mathrm{F} / \mathrm{F}}\right)$ [Scheller et al., 2010]. No bone changes were noted in Col2.3-Cre-driven $\mathrm{ObRb}$ knockout animals $\left(2.3^{\mathrm{Cre}+\mathrm{F} / \mathrm{F}}\right)$. The Col2.3 and Col3.6 promoters are derived from full-length collagen 1A1 (Col1A1) [Krebsbach et al., 1993]. Col3.6 contains a 3.6-kb fragment $(-3,521$ to +115$)$ of the Col1A1 gene. Col2.3 consists of approximately $2.3 \mathrm{~kb}$ of CollA1 DNA upstream of the transcription start site [Krebsbach et al., 1993]. Col2.3Cre is known to drive loxP recombination in osteoblast and odontoblast populations [Kalajzic et al., 2002; Liu et al., 2004]. Col3.6-Cre in marrow shows recombination in an earlier mesenchymal precursor cell (MPC) and its downstream progeny [Liu et al., 2004]. There is also evidence that Col3.6-Cre induces nonspecific recombination in other tissues including tendon, muscle, skin, and adipose tissue [Liu et al., 2004; Scheller et al., 2010].

Leptin is an adipokine and central regulator of food intake and metabolism [Pelleymounter et al., 1995]. The development of a leptin-signaling related bone phenotype is thought to have 2 potential sources. The first, and most common, occurs due to alterations in leptin signaling in the brain [Ducy et al., 2000]. Femur length is shortened in both leptin-deficient $\mathrm{Ob} / \mathrm{Ob}$ and $\mathrm{ObRb}$ knockout $(\mathrm{KO}) \mathrm{Db} / \mathrm{Db}$ mice as well as mice with a point mutation in $\mathrm{ObRb}$ that prohibits Stat 3 signaling [Myers, pers. commun.; Hamrick et al., 2004; Ealey et al., 2006; Scheller et al., 2010]. Femur length deficits in leptin-deficient $\mathrm{Ob} / \mathrm{Ob}$ mice can be fully corrected after 15 weeks by leptin gene therapy in the brain [Iwaniec et al., 2007], and can also be partially restored by peripheral intraperitoneal (IP) injection of $50 \mu \mathrm{g} /$ day leptin for 4 weeks [Steppan et al., 2000]. The second possible mechanism of leptin-mediated bone changes occurs when leptin acts directly on a peripheral cell such as the MPC to regulate differentiation and subsequent bone formation [Scheller et al., 2010].

Generation of a mouse model with floxed ObRb has allowed the use of conditional ObRb KO mice to determine the relative contributions of the central and peripheral mechanisms of leptin regulation on bone formation [McMinn et al., 2004]. Leptin- or ObRb-deficient mice have decreased femur length that is due to central depletion of leptin signaling. In contrast, the femur length of our 3.6 $6^{\mathrm{Cre}+\mathrm{F} / \mathrm{F}}$ mice was increased by $5.4 \pm 0.16 \%$ in addition to approximately $80 \%$ increases in the trabecular bone volume fraction and bone mineral density [Scheller et al., 2010]. We hypothesize that this is driven by a peripheral deletion of leptin receptors on the MPC, but, due to the nonspecific recombination in other tissues, we cannot yet rule out the contribution of central leptin actions. In this study we systematically investigated the ability of both Col2.3-Cre and Col3.6-Cre to drive nonspecific loxP recombination in the brain. In addition, to determine the contribution of central leptin signaling to the Col3.6 bone phenotype, we evaluated the ability of leptin to force recombination in leptin-responsive PStat3-positive neurons.

\section{Materials and Methods}

\section{Animals}

All procedures were approved by the University Committee on the Use and Care of Animals. Col2.3-Cre and Col3.6-Cre mice were obtained from Dr. Fei Liu (University of Michigan) [Liu et al., 2004]. ROSA-enhanced green fluorescent protein (EGFP) mice were obtained from Jackson Laboratory (Stock No. 004077). ColCre mice were crossed with ROSA reporter mice, and 3 F1 pups per promoter were analyzed at 12-16 weeks of age. The Cre genotyping primers were: CreF CGCAGAACCTGAAGATGTTCGCGATTA; CreR TCTCCCACCGTCAGTACGTGAGATATC. As described previously [Scheller et al., 2010], 3.6 ${ }^{\mathrm{Cre}+\mathrm{F} / \mathrm{F}}$ mice were generated.

\section{Leptin Injection}

For colocalization studies, mice were anesthetized with isoflurane, and a 26-gauge intracerebral ventricular cannula was implanted into the lateral ventricle at $\mathrm{A} / \mathrm{P}-0.34, \mathrm{M} / \mathrm{L}-1.0$, and $\mathrm{D} / \mathrm{V}$ -2.4 [Franklin and Paxinos, 1997]. The cannula pedestal was affixed to the skull with surgical adhesive, the wound was closed, and a dummy injector was placed for the duration of recovery. The recovery time was 1 week with analgesia (Buprenex) prior to and $12 \mathrm{~h}$ after surgery. Mice were then treated with $3 \mu \mathrm{g}$ leptin $[3 \mu \mathrm{l}$ of $1 \mathrm{mg} / \mathrm{ml}$ leptin (a generous gift from Amylin) injected at a rate of $1 \mu \mathrm{l} / \mathrm{min}]$.

For aged 3.6 $6^{\mathrm{Cre}+\mathrm{F} / \mathrm{F}}$ studies (fig. 1), 10-month-old mice were injected IP with $5 \mathrm{mg} / \mathrm{kg}$ leptin. Mice were anesthetized $2 \mathrm{~h}$ after treatment with an overdose of IP pentobarbital, and they were transcardially perfused with $10 \%$ normal buffered formalin.

\section{Immunohistochemistry}

Brains were removed, postfixed overnight, and dehydrated in a $30 \%$ sucrose solution. Immunostaining was performed as described previously [Leinninger et al., 2009]. A freezing microtome was used to collect $30-\mu \mathrm{m}$ serial coronal sections in 4 consecutive series. Brain sections were incubated in rabbit anti-P-STAT3 (1:250; Cell Signaling) and chicken anti-GFP (1:1,000; AbCam) overnight at room temperature and then visualized using a biotin-conjugated secondary antibody (1:250; Jackson ImmunoResearch) and DAB (Vectastain ABC kit; Thermo Scientific) or secondary immunofluorescence using species-specific Alexa-488 or Alexa-568 antibodies (1:200; Invitrogen). Stained sections were mounted onto gelatin-coated slides using ProLong Gold Antifade reagent (Invitrogen). 


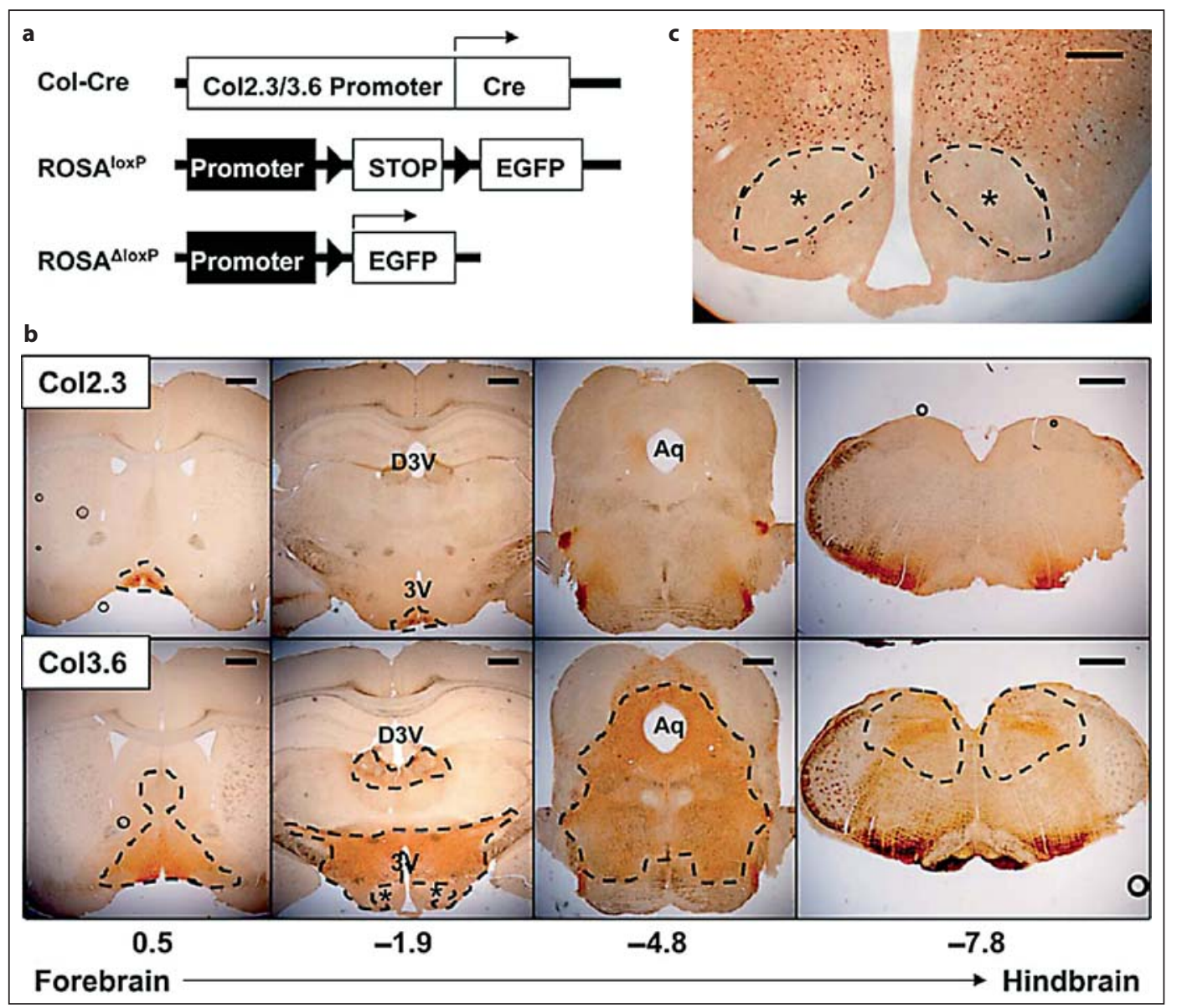

Fig. 1. a Col2.3-Cre and Col3.6-Cre mice were bred with GFP ROSA reporter mice. Cre-driven recombination of loxP sites (triangles) facilitated the expression of EGFP. $\mathbf{b}$ The resulting expression of EGFP in the brain was analyzed. Circular artifacts represent bubbles accrued during section mounting. Scale bars $=500 \mu \mathrm{m}$. c Col3.6-Cre-driven neural deletion was nearly absent in the VMH. Scale bar $=100 \mu \mathrm{m}$. * VMH.

Image Analysis and Statistics

Sections were imaged using NIS-Elements on a Nikon Eclipse E600 and grouped into composite images for each brain region to be analyzed. ImageJ was used to threshold the composites and determine the number of positive neurons per unit of area in each brain region [Abramoff et al., 2004]. A 2-tailed, homoscedastic t test was used to determine significance between control and experimental groups at $\mathrm{p}<0.050$. Values are reported as means \pm the standard deviation.

\section{Results}

Both Col3.6-Cre and Col2.3-Cre Induce Neural loxP Recombination

Col2.3-Cre and Col3.6-Cre mice were bred with ROSA-EGFP reporter mice. Cre recombinase forces the recombination of loxP sites and excision of the intervening DNA in tissues that express Col2.3 or Col3.6. Deletion of loxP removed a stop sequence in front of an EGFP locus (fig. 1a) [Mao et al., 2001]. Expression of EGFP in the brains of $2.3^{\text {ROSA-EGFP }}$ and 3.6 $6^{\text {ROSA-EGFP }}$ mice was analyzed indirectly with an anti-GFP antibody. Few positive neural cells in the $2.3^{\text {ROSA-EGFP }}$ mice were noted; most of the expression was located near the base of the brain around the bottom of the third ventricle (3V), including the arcuate nucleus (Arc) of the hypothalamus (fig. 1b). The 3.6 ${ }^{\text {ROSA-EGFP }}$ mice showed significantly more positive cells in regions spanning from the forebrain to the hindbrain centered predominantly around the $3 \mathrm{~V}$, dorsal $3 \mathrm{~V}$ (D3V), and aqueduct (Aq) (fig. 1b). In the hypothalamus, the ventral medial hypothalamus $(\mathrm{VMH})$ was specifically negative for EGFP+ neurons (fig. 1b, c). 

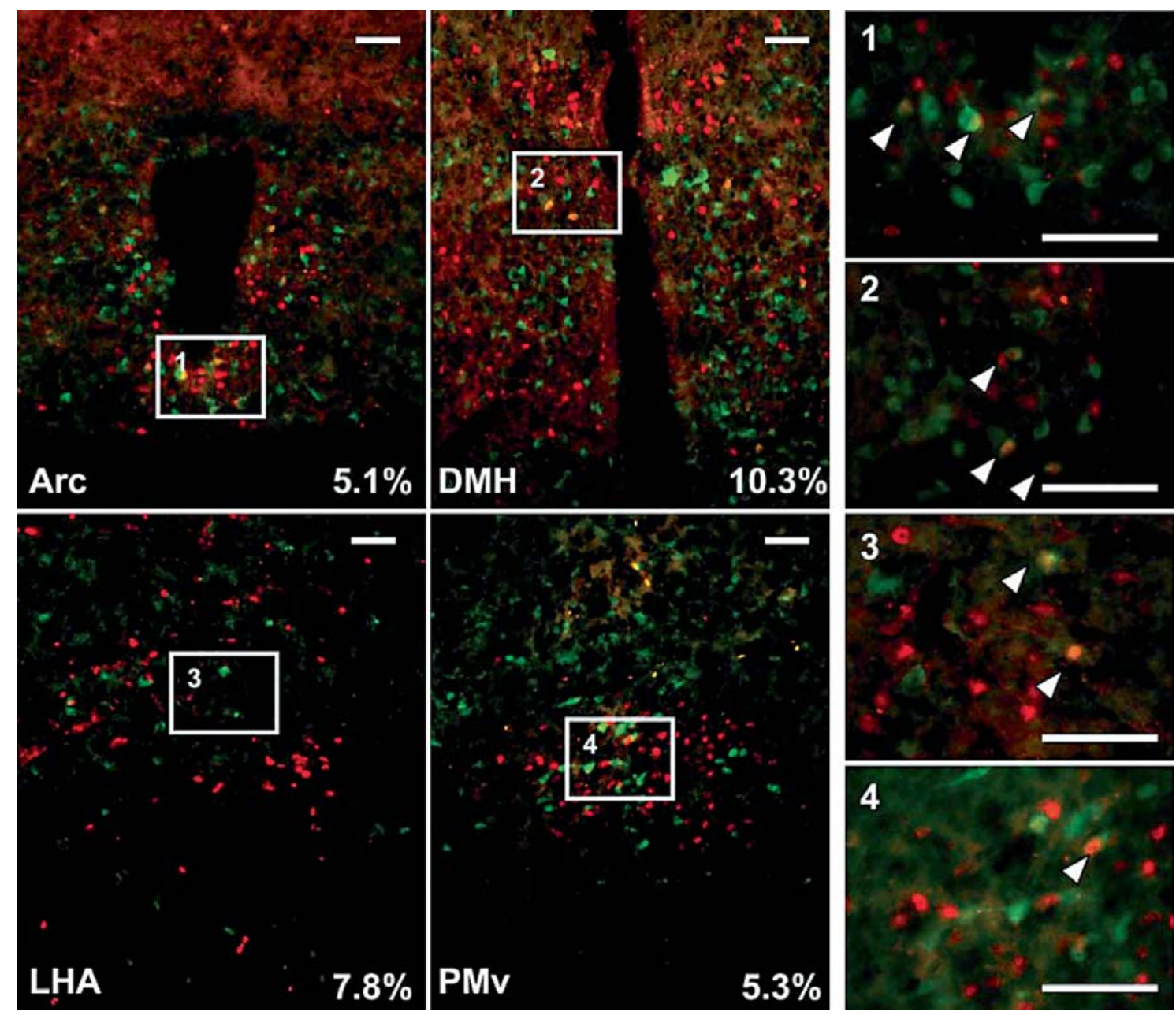

Fig. 2. Mice (3.6 ROSA-GFP $)$ were treated with leptin injected directly into the lateral ventricle of the brain. Leptinresponsive P-Stat3 neurons are pictured in red and EGFP-positive neurons in green. Approximately $5-10 \%$ colocalization of P-Stat3 neurons with EGFP was noted in the Arc, DMH, LHA, and PMv. Scale bars $=50 \mu \mathrm{m}$.

\section{Col3.6 Induces Mild Colocalization with}

\section{Leptin-Responsive Neurons}

Injection of leptin IP or directly into the lateral ventricle produced a robust P-Stat 3 response in hypothalamic brain regions including the posterior hypothalamus, ventral premammillary nucleus (PMv), Arc, dorsal medial hypothalamus (DMH), VMH, and lateral hypothalamic area (LHA), consistent with previous reports [Faouzi et al., 2007]. We also examined representative sections from 1 of 4 series per brain including the ventral tegmental area and preoptic areas. An average of 5-10\% of P-Stat3-positive neurons colocalized with EGFP+ cells in the Arc, VMH, PMv, and LHA (fig. 2). When the procedure was repeated with Col2.3 mice, very little colocal- ization was noted (0-1\%); the highest levels were present in the Arc (fig. $1 \mathrm{~b}$ and data not shown).

\section{Aged 3.6 ${ }^{\mathrm{Cre}+F / F}$ Mice Have an Intact but Decreased}

\section{Central Leptin Response}

The presence of colocalization of P-Stat3 and EGFP+ neurons implies that leptin signaling may be decreased in $3.6^{\mathrm{Cre}+\mathrm{F} / \mathrm{F}}$ mice. In addition, it has been previously reported that obesity enhances leptin resistance [Faouzi et al., 2007]. Therefore, we examined the combination of ObRb deletion and leptin resistance on the P-Stat 3 response in 10-month-old male 3.6 $6^{\mathrm{Cre}+\mathrm{F} / \mathrm{F}}$ mice. We found that $3.6^{\mathrm{Cre}+\mathrm{F} / \mathrm{F}}$ mice had increased baseline P-Stat 3 staining in regions such as the PMv (fig. $3 \mathrm{a}, \mathrm{b}$ ). The $3.6^{\mathrm{Cre}+\mathrm{F} / \mathrm{F}}$ 
Fig. 3. Leptin induces a P-Stat 3 response in both WT and 3.6 ${ }^{\mathrm{Cre}+\mathrm{F} / \mathrm{F}}$ mice. Ten-monthold mice were injected IP with $5 \mathrm{mg} / \mathrm{kg}$ leptin for $2 \mathrm{~h}$ before perfusion and analysis. a Representative images from the posterior hypothalamus and Arc; $n=3$ per group. Scale bars $=50 \mu \mathrm{m}$. b Additional quantified data from hypothalamic brain regions. Statistics: a = significant over matched PBS; $b=$ significant over control PBS; $c$ = significant over control leptin; $\mathrm{d}=$ nonsignificant trend over the matched control, $\mathrm{p}<0.100$.

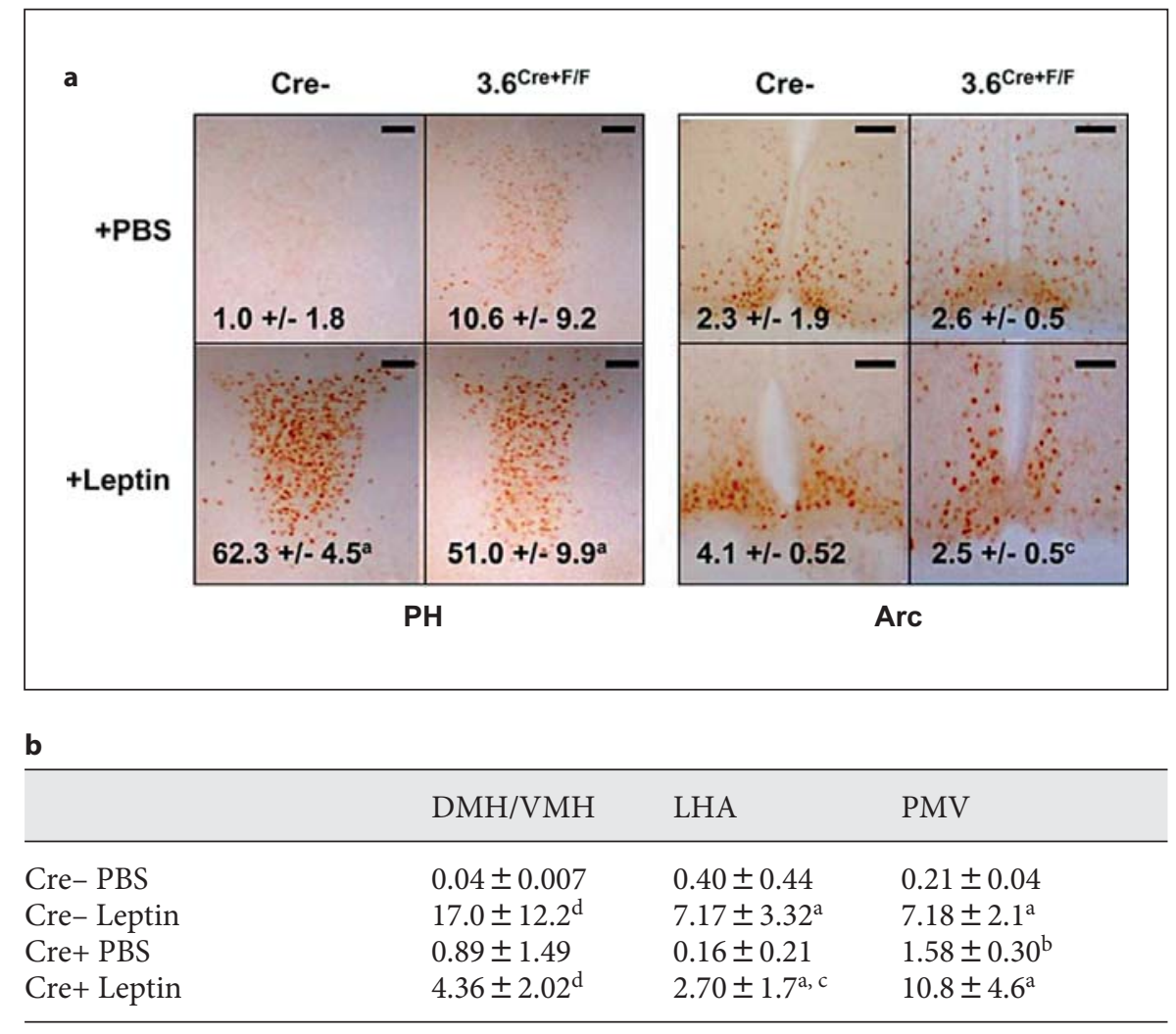

mice also had a decreased P-Stat3 response to IP-delivered leptin in the LHA, Arc, and DMH/VMH when compared to controls (fig. 3a, b). Due to high background PStat 3 staining in the Arc, a significant increase in staining could not be detected after leptin addition in either group (fig. 3a). However, there was a significant reduction of P-Stat3-positive neurons in the Arc of leptin-treated 3.6 $6^{\mathrm{Cre}+\mathrm{F} / \mathrm{F}}$ mice when compared to controls (fig. 3a).

\section{Discussion and Conclusions}

The first goal of this study was to examine the expression of Col3.6 and Col2.3 promoters in the brain. We found significant Cre-induced loxP recombination with both promoters, though Col3.6-Cre induced much more widespread deletion that centered on the $3 \mathrm{~V}, \mathrm{D} 3 \mathrm{~V}$, and Aq. Unanticipated neural expression is not unique to these promoters and has also been found with the previously-assumed adipose-specific Fabp4-Cre (Jackson Laboratory stock No. 005069) [Heffner and Sharma, 2010]. These unexpected findings highlight the need to perform a full-body analysis when characterizing tis- sue-specific transgenic animals. The second aim of this study was to follow up on our original publication [Scheller et al., 2010] and address the following question: does $\mathrm{ObRb}$ deletion in the brain contribute to the bone phenotype of the $3.6^{\mathrm{Cre}+\mathrm{F} / \mathrm{F}}$ mice? Colocalization studies revealed that while Col3.6 was expressed widely in the brain, the neurons that were affected only overlapped with leptin-responsive P-Stat 3 neurons in $5-10 \%$ of cases. As previously discussed, complete ObRb KO mice have a decreased femur length. It is thus unlikely that the removal of $5-10 \%$ of central leptin signaling would result in the opposite phenotype of increased femur length through a mechanism that involves direct sympathetic regulation of osteoblasts or osteoclasts [Ducy et al., 2000].

\section{Acknowledgments}

This study was supported by R01-DE13835 (P.H.K.), F30DE019577 (E.L.S.), and NIH DK57768 (M.G.M.). 


\section{References}

Abramoff, M.D., P.J. Magelhaes, S.J. Ram (2004) Image Processing with ImageJ. Biophotonics Int 11: 36-42.

Ducy, P., M. Amling, S. Takeda, M. Priemel, A.F. Schilling, F.T. Beil, J. Shen, C. Vinson, J.M. Rueger, G. Karsenty (2000) Leptin inhibits bone formation through a hypothalamic relay: a central control of bone mass. Cell 100 197-207.

Ealey, K.N., D. Fonseca, M.C. Archer, W.E. Ward (2006) Bone abnormalities in adolescent leptin-deficient mice. Regul Pep 136: 9-13.

Faouzi, M., R. Leshan, M. Bjornholm, T. Hennessey, J. Jones, H. Munzberg (2007) Differential accessibility of circulating leptin to individual hypothalamic sites. Endocrinology 148: 5414-5423.

Franklin, K.B.J., G. Paxinos (1997) The Mouse Brain in Stereotaxic Coordinates. San Diego, Academic Press.

Hamrick, M.W., C. Pennington, D. Newton, D. Xie, C. Isales (2004) Leptin deficiency produces contrasting phenotypes in bones of the limb and spine. Bone 34: 376-383.

Heffner, C., Y. Sharma (2010) B6.Cg-Tg(Fabp4 cre)1Rev/J (Stock No 005069). Bar Harbor Jackson Laboratory.
Iwaniec, U.T., S. Boghossian, P.D. Lapke, R.T. Turner, S.P. Kalra (2007) Central leptin gene therapy corrects skeletal abnormalities in leptin-deficient ob/ob mice. Peptides 28: 1012-1019.

Kalajzic, Z., P. Liu, I. Kalajzic, Z. Du, A. Braut, M. Mina, E. Canalis, D.W. Rowe (2002) Directing the expression of a green fluorescent protein transgene in differentiated osteoblasts: comparison between rat type I collagen and rat osteocalcin promoters. Bone 31 : 654-660.

Krebsbach, P.H., J.R. Harrison, A.C. Lichtler, C.O. Woody, D.W. Rowe, B.E. Kream (1993) Transgenic expression of COL1A1-chloramphenicol acetyltransferase fusion genes in bone: differential utilization of promoter elements in vivo and in cultured cells. Mol Cellular Biol 13: 5168-5174.

Leinninger, G.M., Y.H. Jo, R.L. Leshan, G.W. Louis, H. Yang, J.G. Barrera, H. Wilson, D.M. Opland, M.A. Faouzi, Y. Gong, J.C. Jones, C.J. Rhodes, S. Chua, Jr., S. Diano, T.L. Horvath, R.J. Seeley, J.B. Becker, H. Munzberg, M.G. Myers, Jr. (2009) Leptin acts via leptin receptor-expressing lateral hypothalamic neurons to modulate the mesolimbic dopamine system and suppress feeding. Cell Metab 10: 89-98.
Liu, F., H.W. Woitge, A. Braut, M.S. Kronenberg, A.C. Lichtler, M. Mina, B.E. Kream (2004) Expression and activity of osteoblast-targeted Cre recombinase transgenes in murine skeletal tissues. Int J Dev Biol 48: 645-653.

Mao, X., Y. Fujiwara, A. Chapdelaine, H. Yang, S.H. Orkin (2001) Activation of EGFP expression by Cre-mediated excision in a new ROSA26 reporter mouse strain. Blood 97: 324-326.

McMinn, J.E., S.M. Liu, I. Dragatsis, P. Dietrich, T. Ludwig, S. Eiden, S.C. Chua, Jr. (2004) An allelic series for the leptin receptor gene generated by CRE and FLP recombinase. Mamm Genome 15: 677-685.

Pelleymounter, M.A., M.J. Cullen, M.B. Baker, R. Hecht, D. Winters, T. Boone, F. Collins (1995) Effects of the obese gene product on body weight regulation in ob/ob mice. Science 269: 540-543

Scheller, E.L., J. Song, M.I. Dishowitz, F.N. Soki, K.D. Hankenson, P.H. Krebsbach (2010) Leptin functions peripherally to regulate differentiation of mesenchymal progenitor cells. Stem Cells 28: 1071-1080.

Steppan, C.M., D.T. Crawford, K.L. ChidseyFrink, H. Ke, A.G. Swick (2000) Leptin is a potent stimulator of bone growth in ob/ob mice. Regul Peptides 92: 73-78. 